\title{
Laser-induced fluorescence emission (LIFE) from Lake Fryxell (Antarctica) cryoconites
}

\author{
Birgit SATTLER, ${ }^{1}$ Michael C. STORRIE-LOMBARDI, ${ }^{2}$ Christine M. FOREMAN, ${ }^{3}$ \\ Markus TILG, ${ }^{1}$ Roland PSENNER ${ }^{1}$ \\ ${ }^{1}$ Institute of Ecology, University of Innsbruck, Technikerstrasse 25, A-6020 Innsbruck, Austria \\ E-mail: birgit.sattler@uibk.ac.at \\ ${ }^{2}$ Kinohi Institute, 798 North Mar Vista Avenue, Pasadena, CA 91104, USA \\ ${ }^{3}$ Center for Biofilm Engineering and Department of Land Resources and Environmental Sciences, Montana State University, \\ Bozeman, MT 59717, USA
}

\begin{abstract}
Laser-induced fluorescence emission (LIFE) images were obtained in situ from a $27 \mathrm{~cm}$ long ice core at Lake Fryxell, Antarctica. The excitation was accomplished with a simple $532 \mathrm{~nm}$ green laser pen light, and the fluorescence images were captured with a small compact digital camera. The targets for the experiment were mm-scale cryoconite assemblages found in the ice covers of this perennially frozen Antarctic lake. The fluorescence response originates from photo-pigments in cyanobacteriadominated cryoconite assemblages with phycoerythrin (PE) exhibiting the optimal target cross section. This inexpensive, low-mass, low-energy method avoids manipulation of the in situ habitat and individual target organisms and does not disturb the microbial community or the surrounding ice matrix. We establish the correlation between fluorescence intensity and PE concentration. We show that cryoconite fluorescence response does not appear to decrease with depth in the ice cover, in agreement with similar findings at Lake Untersee, a perennially ice-covered lake in Dronning Maud Land, Antarctica. Optical reflection and refraction events at the air/ice interface can complicate quantitative estimates of total pigment concentrations. Laser targeting of a single $\mathrm{mm}$-scale cryoconite can result in multiple neighboring excitation events secondary to reflection and refraction phenomena in the multiple air/ice interface of the bubbles surrounding the primary target.
\end{abstract}

\section{INTRODUCTION}

The lake-ice covers and glaciers of Earth's cryosphere are home to complex microbial communities (Priscu and others, 1998; Psenner and Sattler, 1998; Psenner and others, 1999; Priscu and Christner, 2004; Sattler and others, 2004). Aeolian transport deposits dust particles onto these frozen surfaces containing humic material and microbial life, including photosynthetic cyanobacteria (Psenner, 1999; Sattler and others, 2001; Porazinska and others, 2004; Foreman and others, 2007). Dust grains rich in organic molecules exhibit high coefficients of friction, increasing the likelihood that the assemblage will adhere to the ice surface (Takeuchi and others, 2001; Takeuchi and Li, 2008). These darker grains mixed with inorganic material efficiently absorb solar energy, producing a local temperature elevation. The ice beneath the assemblage melts by solar heating and the debris sinks into the ice. The assemblage is soon covered by a new icy surface as the surficial portion of the melt freezes (Tranter and others, 2004). However, where the ice is in contact with the warmer humic material, an unfrozen layer of water around the particle provides a liquid nutrient-rich layer sufficient to support a microbial community (Priscu and others, 1998; Price, 2007). These accumulations, first called cryoconites (from the Greek kryos, 'icy cold', and konia, 'dust') by the Swedish explorer A.E. Nordenskjöld in 1870 (Miteva, 2008), range in scale from detritus surrounding massive boulders to small grains a few $\mu \mathrm{m}$ in diameter. Cryoconite microbial assemblages exhibit significant variety, but appear to be dominated by important photosynthetic primary producers (Tranter and others, 2004; Hodson and others, 2005; Foreman and others, 2007; Hodson and others, 2008), particularly cyanobacteria (Säwström and others, 2002; Anesio and others, 2009, 2010).

The sensitivity of many psychrophiles to even moderate changes in temperature, and the logistical difficulties associated with either in situ analysis or sampling make it difficult to study these cryospheric ecosystems. In general, the ice habitat has to be disrupted using techniques that include coring, sawing and melting. Samples are often chosen blindly, with little indication of probable biomass. The need for an in situ non-invasive, non-destructive technique to detect, localize and sample cryosphere biomass in the field is therefore of considerable importance.

Laser-induced fluorescence emission (LIFE) occurs when matter absorbs a fraction of an incident laser beam and emits a longer-wavelength (lower-energy) photon. LIFE is arguably the single most sensitive active photonic probe of biomolecules, in either intra- or extracellular targets, that does not require sample preparation, sample destruction, or consumable resources other than power (Asher, 1993). LIFE biosignatures may be obtained as either spectra or images. Epifluorescence microscopy with broadband excitation at 254 and $375 \mathrm{~nm}$, and laser excitation of 532 and $660 \mathrm{~nm}$, is standard equipment for laboratory microbiology. Laser excitation between 220 and $250 \mathrm{~nm}$ produces LIFE signatures for nucleic acids and aromatic amino acids that can be detected by an ultraviolet (UV)-sensitive camera (Nealson and others, 2002) or spectrometer (Bhatia and others, 2008). The technique has been proposed as a method to search for life on Mars (Storrie-Lombardi and others, 2001, 2009) and has been used to detect microbial life in basalt beneath Mauna Kea, Hawaii (Fisk and others, 2003), deep within glacial ice (Price, 2007), and in Greenland ice cores (Rohde 
and others, 2008). LIFE techniques using long-wavelength $(365 \mathrm{~nm})$ UV light-emitting diodes (LEDs) or lasers have been shown to be applicable to the European Space Agency's ExoMars mission to search for polycyclic aromatic hydrocarbons in the Mars regolith (Griffiths and others, 2008; Storrie-Lombardi and others, 2008a,b).

Excitation between 450 and $650 \mathrm{~nm}$ produces LIFE signatures between 500 and $800 \mathrm{~nm}$ in microbial photopigments, including carotenoids, phycobiliproteins and chlorophylls (Blinks, 1954). Phycobiliproteins are found in red algae, cyanobacteria and cryptomonads including species inhabiting ice-covered Antarctic lakes. Red algae and cyanobacteria contain all three types of phycobiliproteins: phycoerythrin (PE), phycocyanin and allophycocyanin (Ong and Glazer, 1991; Samsonoff and MacColl, 2001). Red algae and cyanobacteria also contain chlorophyll a, and cryptomonads contain both chlorophyll $a$ and $c$. In water and ice the spectral distribution of light is shifted to the blue-green, and energies are better absorbed by the biliproteins than by chlorophyll a. Light absorbed by the biliproteins migrates to chlorophyll and then to the photosynthetic reaction centers where they are transformed into chemical energy. The most commonly encountered cyanobacteria of cryptoendolithic lichens in the high-polar regions of Antarctica produce significant fluorescence response to excitation between $436 \mathrm{~nm}$ (Soret band for chlorophyll) and $550 \mathrm{~nm}$, the region of maximum absorption by phycobiliproteins (Erokhina and others, 2002). LIFE spectral signatures of phytoplankton using $532 \mathrm{~nm}$ laser excitation have been obtained from airborne platforms such as NASA's Airborne Oceanographic Lidar since 1979 (Hoge and Swift, 1981). The LIFE signatures obtained with $532 \mathrm{~nm}$ excitation have been attributed primarily to PE, a phycobiliprotein with optimal excitation cross section between 500 and $570 \mathrm{~nm}$ (Gantt, 1969).

Signal analysis of the LIFE images obtained from the ice cover of the perennially frozen Lake Untersee, Dronning Maud Land, East Antarctica, revealed no significant decrease in photosynthetic biomass in the first meter of the clear ice (Storrie-Lombardi and Sattler, 2009). If lake ice cryoconites are relatively rich in organic material, as in supraglacial environments (Anesio and others, 2009), and the associated microbial communities include photosynthetic cyanobacteria (Priscu and others, 1998; Psenner and others, 1999; Sattler and others, 2004), then the primary limiting factor for biomass will be the translucency of the ice and the availability of sunlight to provide both the energy necessary to melt the ice surrounding the assemblage and the energy for photosynthesis. Microbial communities dominated by cyanobacteria (Taton and others, 2003) conduct photosynthesis inside the ice cover during a few weeks in the austral summer (Fritsen and Priscu, 1998; Priscu and others, 2005). Clusters of sediments and microbial communities can be observed in the lake ice down to the accumulation zone, i.e. the depth where the solar radiation does not provide enough energy for the melting process. Since photosynthesizing ice covers of, for example, permanently frozen lakes, ice caps and supraglacial environments can cover a substantial portion of the cryosphere, it is crucial to assess the photosynthetic potential of these environments.

We have recently reported initial field trials using a $532 \mathrm{~nm}$ laser excitation and digital single lens reflex (DSLR) camera to detect LIFE signatures in the perennial ice cover of Lake Untersee (Storrie-Lombardi and Sattler, 2009; Sattler and Storrie-Lombardi, 2010). The applicability of the method has been confirmed, but the preliminary work did not explicitly demonstrate the correlation between the LIFE signal strength and pigment concentration.

The first aim of this study is to establish the correlation between LIFE signal strength and pure PE concentration. Secondly, to simplify the acquisition of LIFE images of cryoconites under field conditions, we use a lightweight standard compact digital camera using a standard Bayer color filtering algorithm for color estimation in place of the large DSLR camera with a Foveon chip used in our earlier studies. The Foveon chip does not need to employ Bayer color estimation since it utilizes silicon depth selection to discriminate between red, green and blue photon energies. However, the camera is more expensive, heavier and considerably larger than pocket-sized compact digital cameras. Finally, we have employed the modified field system to test the hypothesis that cryoconite biomass as estimated by LIFE PE signatures remains relatively constant for the first few tens of $\mathrm{cm}$ in the ice cover of an Antarctic lake (Lake Fryxell).

\section{METHODS AND MATERIALS}

\section{Field test sites}

Lake Fryxell is a $4.5 \mathrm{~km}$ long meromictic, permanently icecovered lake in the McMurdo Dry Valleys between Canada and Commonwealth Glaciers at the lower end of Taylor Valley, Victoria Land, East Antarctica $\left(77^{\circ} 10.6^{\prime} \mathrm{S}\right.$, $163^{\circ} 10.1766^{\prime}$ E; Fig. 1). Lakes Fryxell, Hoare and Bonney all lie in Taylor Valley and are the subject of the McMurdo Dry Valleys Long-Term Ecological Research (MCM LTER) program, which is an inter- and multidisciplinary study of the aquatic and terrestrial ecosystems in an ice-free region of Antarctica. Average annual ice-cover thickness is controlled by the rate of freezing of lake water at the bottom of the ice $\left(\sim 30 \mathrm{~cm} \mathrm{a}^{-1}\right)$ and the ablation loss at the ice/air interface via sublimation $\left(\sim 15-60 \mathrm{~cm} \mathrm{a}^{-1}\right)$. On average, the balance of these processes produces $\sim 30 \mathrm{~cm} \mathrm{a}^{-1}$ of net upward movement of the ice (Jaraula and others, 2009). The lake ice cover is almost crystal clear (Fig. 2), although aeolian dust may transiently cover the surface.

\section{Sample collection}

Ice cores $7.25 \mathrm{~cm}$ in diameter were obtained with a handdriven Kovacs ${ }^{\circledR}$ ice corer (MARK III) and were placed into sterile Whirl-Pak ${ }^{\circledR}$ bags (Lactan, Austria) for further processing. Digital images analyzed in this study were obtained during laser excitation of $\mathrm{mm}$-scale cryoconite assemblages in one such extracted core at the locations depicted in Figure 2.

\section{Digital imaging}

In the laboratory, the presence of autotrophic organisms was assessed with a Zeiss Axioplan epifluorescence microscope provided by broadband incoherent illumination with excitation filters centered at 370, 438, 480 and $548 \mathrm{~nm}$. Images were acquired with an Optotronics ZVS-47EC chargecoupled device (CCD) camera. For in situ photography, RGB reflectance and fluorescence images were obtained using a 6-megapixel Sony Cyber Shot DSC W50 compact digital camera (F2.8, 1/8s exposure). 


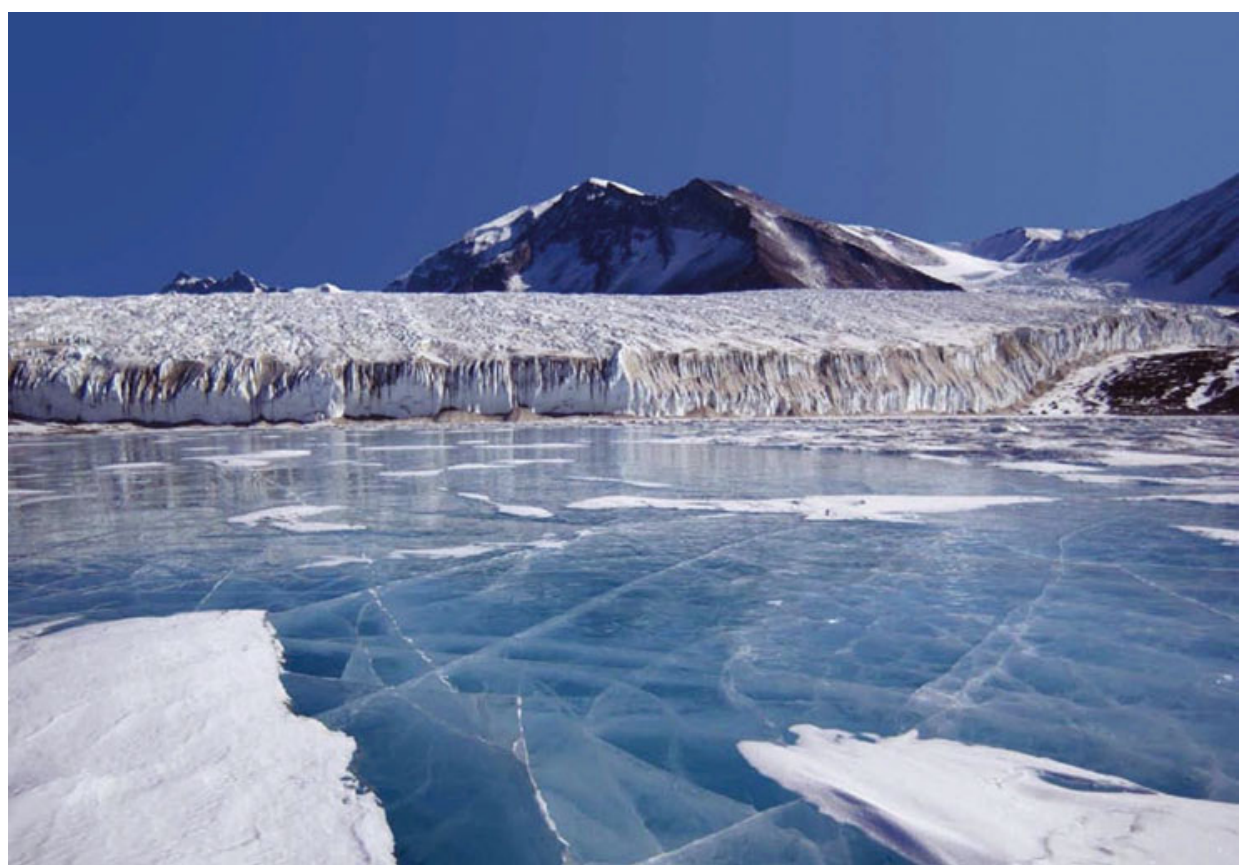

Fig. 1. Lake Fryxell, a $4.5 \mathrm{~km}$ long meromictic, permanently ice-covered lake, located in the McMurdo Dry Valleys between Canada and Commonwealth Glaciers at the lower end of Taylor Valley, Victoria Land, East Antarctica $\left(77^{\circ} 10.6^{\prime}\right.$ S, $163^{\circ} 10.1766^{\prime}$ E). Image source: Antarctic Photo Library, http://photolibrary.usap.gov/AntarcticaLibrary.

\section{Laser excitation}

Target excitation was accomplished with a $532 \mathrm{~nm}$ Class IIA laser with $5 \mathrm{~mW}$ output and powered by two AAA (1.5 V) lithium batteries. The pen light is $16.2 \mathrm{~cm}$ long and weighs $85 \mathrm{~g}$. For in situ excitation of miniature cryoconites in the lake surface ice, the laser beam diameter at target was $\sim 1.0 \pm 0.1 \mathrm{~mm}$.

\section{Calibration with PE standards}

For a set of standardized images, artificial regions of interest (ROIs) were produced by freezing various concentrations of PE (B-phycoerythrin, Invitrogen) dissolved in distilled water, resulting in final PE concentrations of $0.66,2,4,20,40,200$, 400 and 2.000 ng ml-1 in Petri dishes with a diameter of $4 \mathrm{~cm}$. Each concentration was set up in triplicate. Laser excitation and data analysis was performed as described above for field samples.

\section{Data analysis}

Signal processing was performed using the Os $\mathrm{X}$ version of $\mathrm{NIH}$ Image, Image) (software documentation and code is available at http://rsbweb.nih.gov/ij courtesy of the National Institutes of Health, USA). Data were initially acquired from the camera in RGB/JPG format. A circular ROI $5 \mathrm{~mm}$ in diameter centered on the exciting laser was converted to TIFF file format without compression, and split into blue, green and red channels for deconvolution and extraction of the fluorescence response. Analysis of the red, green and blue channel responses to excitation of a non-fluorescing Speculon ${ }^{\circledR}$ control target allowed for the digital removal of bleed-through reflected laser line contamination of the original images. The control response was used to calculate expected differences in the blue and red bands as a function of blue band response for each pixel on the standard when illuminated with $532 \mathrm{~nm}$ light. Pixels were chosen from those exhibiting (1) green channel saturation (i.e. grayscale

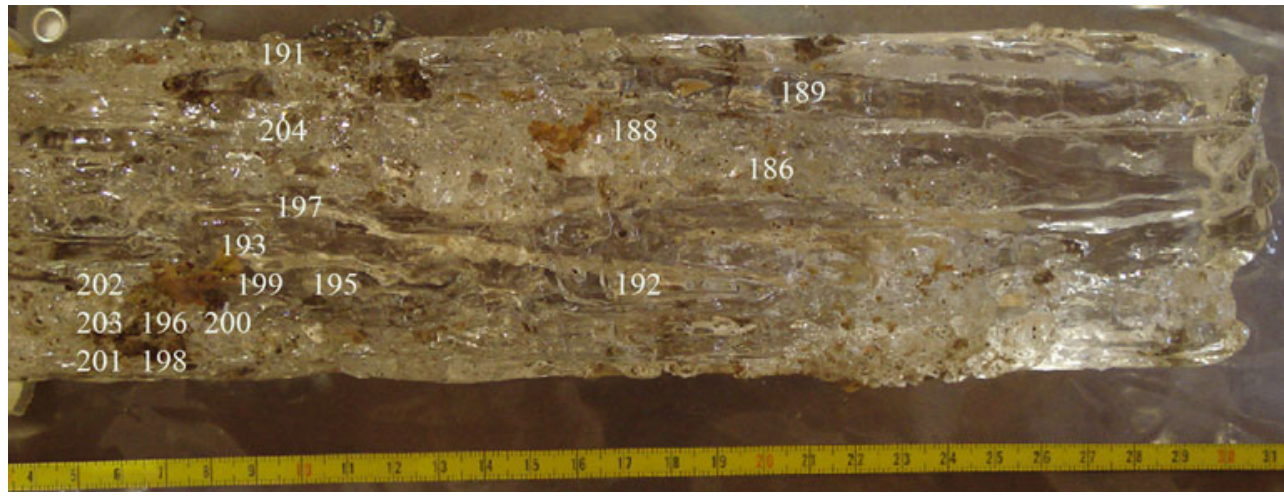

Fig. 2. An ice core from Lake Fryxell, $27 \mathrm{~cm}$ long and $7.5 \mathrm{~cm}$ in diameter, containing multiple mm-scale cryoconites. Numbers refer to the location of the LIFE images obtained for this study. 


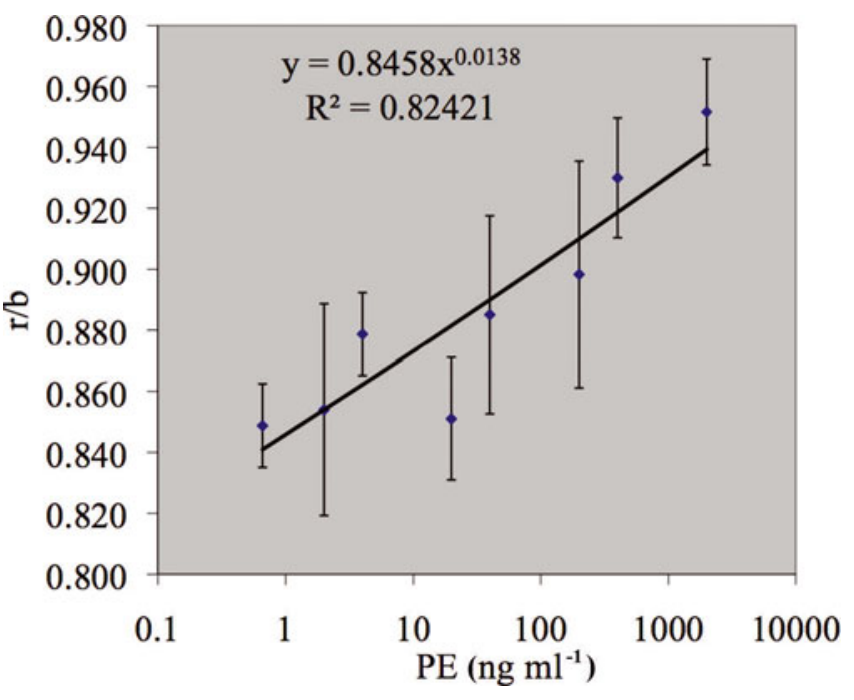

Fig. 3. Calibration set of known PE standards versus ratio of redblue band. The bars are the $1 \sigma$ for the triplicate runs.

(gs) values $\geq 254$ ), our indication of sufficient target excitation, (2) absence of saturation in red and blue channels, and (3) blue channel gs > 180 (below blue channel values of 180 the signal-to-noise levels increase exponentially (Storrie-Lombardi and Sattler, 2009)).

\section{RESULTS}

\section{PE standards}

Figure 3 presents the relative red ( $r$ ) and blue (b) response depicted as the ratio $(r / b)$ of pixel grayscale values (grayscale range 0 to $>254$ ) as a function of PE concentration. $2 \sigma$ error bars for test-retest are depicted. A linear least-squares fit of the data $\left(R^{2}=0.82421\right)$ is shown. Figure 4a depicts the red band Speculon ${ }^{\circledR}$ response, $E_{R}$, as a function of blue band intensity, $E_{\mathrm{B}}$, for all unsaturated blue channel pixels, i.e. where the gs level is $<254$ in the blue channel. The expected red band response, $E_{\mathrm{R}}$, for increasing $E_{\mathrm{B}}$ can be optimally fitted with a simple linear function, $R^{2}=0.9919$. Fluorescence activity did not appear for blue channel activation $<180$ gs. The difference between red and blue channel response, $E_{\mathrm{R}-\mathrm{B}}$, as a function of the blue channel flux appears in Figure $4 \mathrm{~b}$. The difference between predicted and measured $E_{\mathrm{R}-\mathrm{B}}$ is used to generate fluorescence images and estimate the relative photosynthetic biomass in each cryoconite.

The raw RGB image of ice-core target 188 appears in Figure $5 \mathrm{a}$. The green glow in this image is the product of a combination of laser backscatter and fluorescence. Red, green and blue channels are extracted for a ROI $5 \mathrm{~mm}$ in diameter (Fig. 5b). LIFE image signatures (Fig. 5c) are obtained by comparing the red channel response as a function of blue activity in the target with the response in the Speculon control (Fig. $5 \mathrm{~d}$ ). Only $E_{\mathrm{R}-\mathrm{B}}$ values more than two standard deviations above the predicted value for a given level of blue channel response are considered significant. Subtracting the predicted red channel grayscale image from the recorded image produces a light curve map of the ROI (Fig. 5e). Such a plot provides an estimate of the spatial distribution of the photosynthetic community. The response measured for the Speculon ${ }^{\circledR}$ control appears in Figure $5 f$ for comparison. Each of the sites noted in Figure 2 was analyzed. Fluorescence response in units of integrated
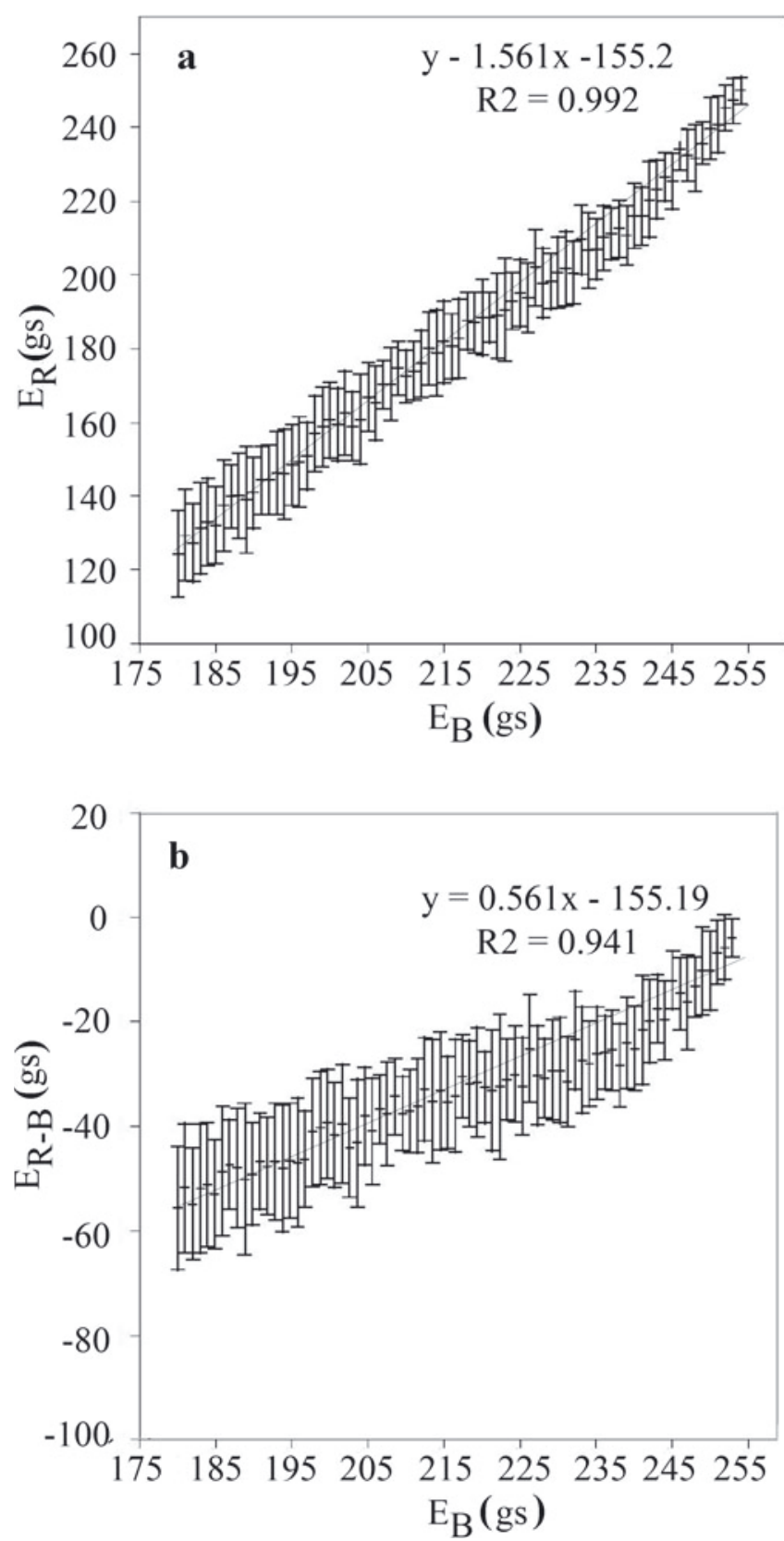

Fig. 4. (a) Sony CCD red channel excitation $\left(E_{R}\right)$ as a function of blue channel excitation $\left(E_{B}\right)$ for gs values $100<E_{R}<255$ and $180<E_{\mathrm{B}}<255$. (b) The difference in red and blue channel response as a function of blue channel excitation.

$\mathrm{gs} \mathrm{mm}^{-2}$ for each cryoconite is reported in Table 1 and plotted as a function of depth below the ice surface in Figure 6. Again, only those $E_{\mathrm{R}-\mathrm{B}}$ values more than two standard deviations above red channel response predicted in the absence of fluorescence are considered significant. The data show that there is no significant decline in fluorescence response to $27 \mathrm{~cm}$ depth in the Lake Fryxell ice core.

Light profiles for fluorescence images used in this study are shown in Figure 7. The Speculon ${ }^{\circledR}$ control light profiles are also provided. The $5 \times 5 \mathrm{~mm}$ fluorescence image used to generate each set of light curves appears in the upper left corner of each light curve graphic. Analysis of these light curves reveals discrete concentrations of fluorescence activity, with light cone diameters ranging from 0.5 to $2.4 \mathrm{~mm}$. There is significant variation in the summed response, most certainly a result of photon scattering, with 

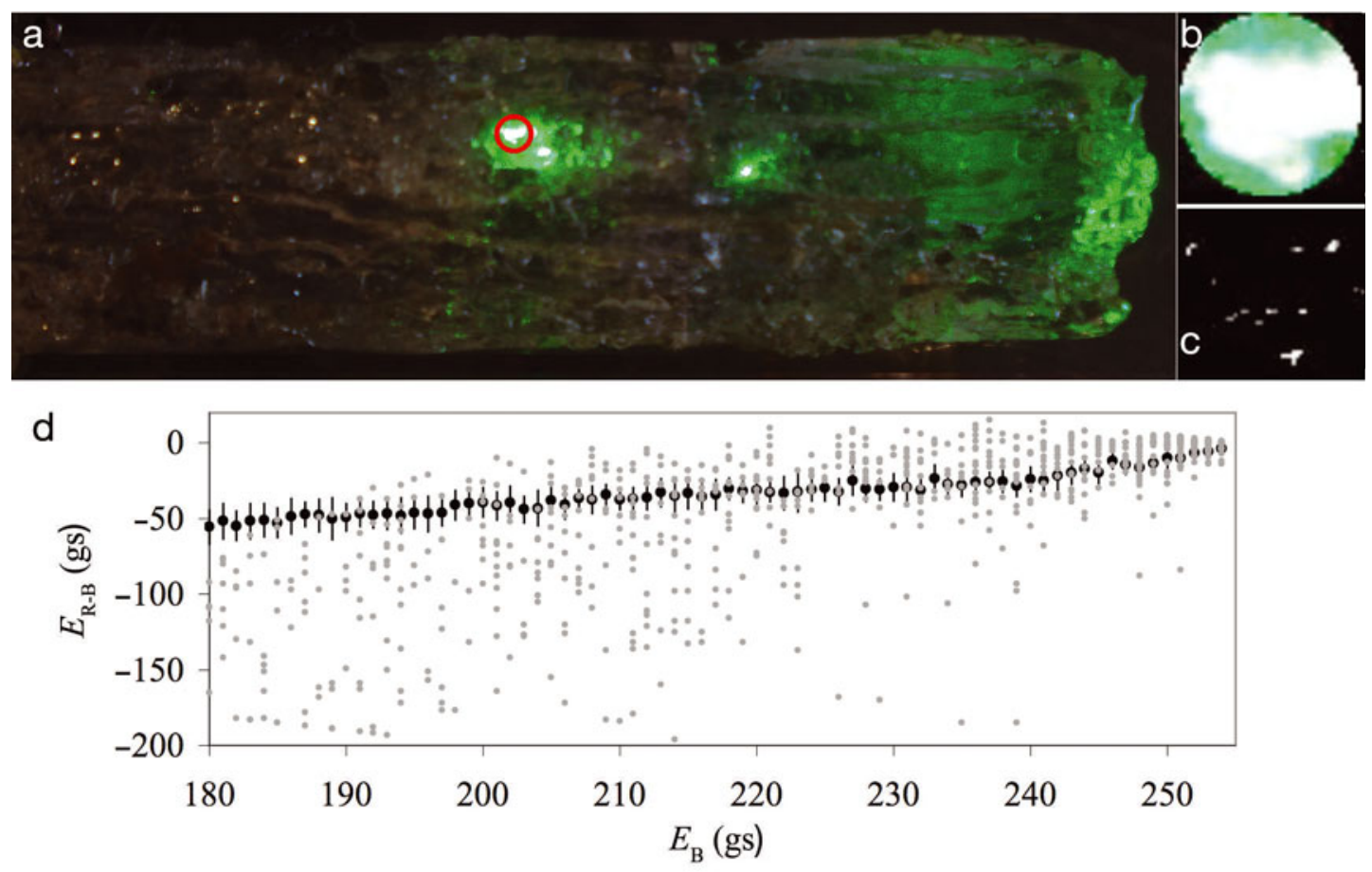

\section{- Speculon · Cryoconite 188}

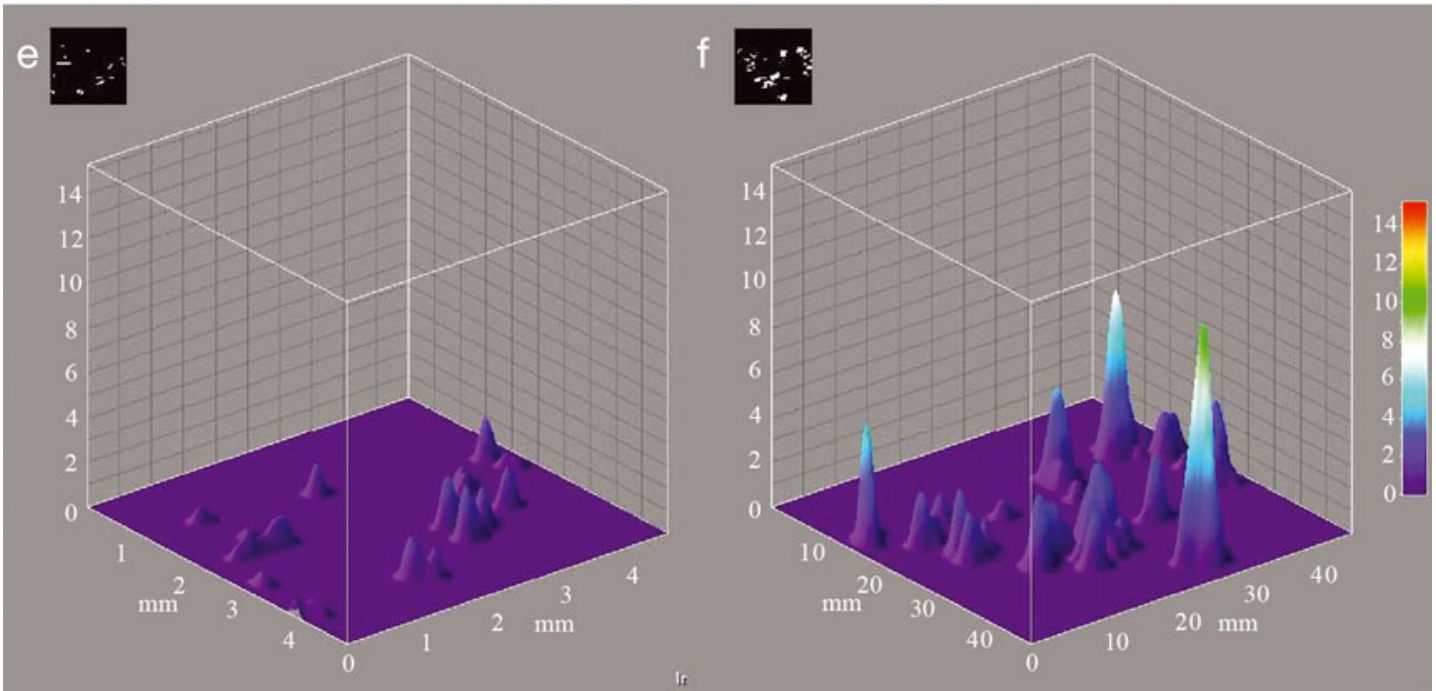

Fig. 5. (a) The raw RGB image of ice-core target 188 exhibits a combination of scatter and fluorescence. (b) Red, green and blue channels extracted for a ROI $5 \mathrm{~mm}$ in diameter. (c-e) A LIFE image signature $E_{\mathrm{R}-\mathrm{B}}>0$ (c) was obtained by comparing the red channel response predicted in the absence of fluorescence with the measured response both anaytically (d) and by subtracting the predicted red channel grayscale image from the recorded image (e). (f) The response measured for the Speculon ${ }^{\mathbb{R}}$ control.

targets generating a mean $E_{\mathrm{R}-\mathrm{B}}=1.92 \pm 1.13, n=28$. The signal-to-noise ratios for individual clusters of activity are even more variable, ranging from 1 (signal not distinguishable from that of the Speculon control) to $>10$. It should be noted that three of the target sites produced multiple regions of excitation from a single laser beam (targets 200, 202 and 204) as a result of air/ice interface reflection and refraction events. For such multiple-response sites, individual images were extracted for each ROI.

\section{DISCUSSION AND CONCLUSIONS}

During periods of global glaciation (Kirschvink and others, 2000), the Earth's cryosphere may have served as a last refuge for photosynthetic life (Vincent and HowardWilliams, 2000; Priscu and Christner, 2004). Cryoconite microbial communities have adapted to short growing seasons, high UV radiation loads, freeze-thaw cycles, and organic resources dependent on limited photosynthetic primary production (Tranter and others, 2004). Cryoconite assemblages and their icy ecosystems have been proposed as a model for understanding the challenges microbial life would face on an earlier warmer, wetter Mars (Horneck, 2000). Multiple efforts are currently underway to devise non-destructive in situ and remote detection technology to explore life in ice both on Earth and on other terrestrial planets (Junge and others, 2004a,b; Tung and others, 2006; Žukauskas and others, 2008). Many of these efforts are 
Table 1. Fluorescence response in units of integrated $\mathrm{gs} \mathrm{m}^{-2}$ for each cryoconite.

\begin{tabular}{lcc}
\hline Image & $\begin{array}{c}\text { Depth } \\
\text { mm }\end{array}$ & $\begin{array}{c}\text { Fluorescence } \\
\text { gs mm }^{-2}\end{array}$ \\
\hline 189 & 100 & 1.67 \\
186 & 101 & 1.53 \\
192 & 158 & 1.23 \\
188 & 159 & 4.19 \\
197 & 214 & 2.72 \\
191 & 214 & 1.75 \\
$204 \mathrm{~b}$ & 223 & 4.50 \\
$204 \mathrm{a}$ & 225 & 1.96 \\
$200 \mathrm{c}$ & 234 & 1.33 \\
$200 \mathrm{~b}$ & 238 & 1.29 \\
198 & 238 & 0.93 \\
195 & 243 & 3.70 \\
$199 \mathrm{~b}$ & 245 & 1.42 \\
193 & 245 & 2.54 \\
$199 \mathrm{a}$ & 245 & 1.57 \\
201 & 249 & 2.87 \\
$200 \mathrm{a}$ & 251 & 2.31 \\
196 & 258 & 1.97 \\
$202 \mathrm{c}$ & 262 & 0.58 \\
203 & 262 & 1.29 \\
$202 \mathrm{a}$ & 263 & 0.31 \\
$202 \mathrm{~b}$ & 264 & 0.52 \\
& & \\
& &
\end{tabular}

modifications of familiar laboratory techniques that are now beginning to prove useful and reliable in the field. The current work is simply a field macroscopic extension of the microscopic epifluorescence techniques commonly employed in microbiology and ecology laboratories for the past six decades.

This work, and earlier pilot studies in Dronning Maud Land reported by Storrie-Lombardi and Sattler (2009) and Sattler and Storrie-Lombardi (2010) have demonstrated that a green laser induces fluorescence in photosynthetically active pigments within liquid water and ice covers of perennially ice-covered Antarctic lakes. Data presented here document a strong linear correlation of fluorescence response measured by $\mathrm{r} / \mathrm{b}$ ratios in a simple $\mathrm{RGB}$ image acquired with an inexpensive, small commercial compact digital camera. Clearly, laser-induced fluorescence emission is a promising non-invasive tool for estimating the photosynthetic pigment concentration inside a range of ice habitats. We believe that this is the most realistic technique for assessing the microbial potential of such ice covers, but the method is still in its infancy. The effects of several confounding phenomena need to be critically evaluated. First, the simple $\mathrm{r} / \mathrm{b}$ ratio can, like any ratio, hide the answer to a central question: is an observed change due to an increase or decrease in either variable, or is it due to a complex change in both? Second, cryoconites are rich in a wide variety of organic products capable of absorbing in red, green and blue spectral regions. As a result, they can absorb and scatter both the incoming laser photons and/or PE fluorescing photons. Since environmental ice structures harbor not just microbes, but also a mixture of organic and inorganic debris, calibration is necessary using particles of various source, size and concentration. In the calibration performed in the current effort, scattering was produced

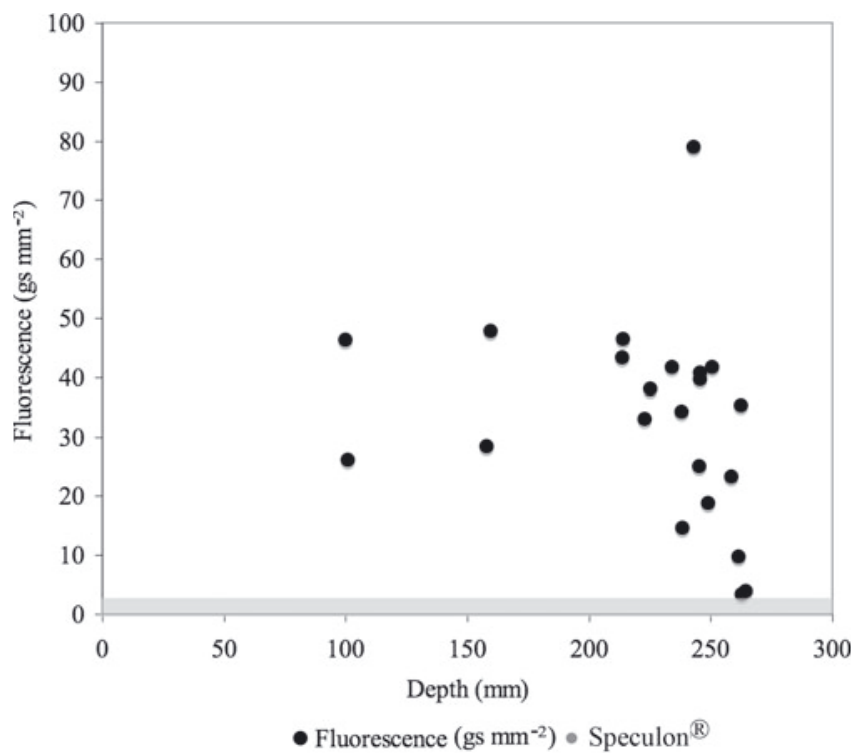

Fig. 6. Fluorescence response in units of summed gs values $\mathrm{mm}^{-2}$ depicted as a function of depth below the ice surface. Only those $E_{\mathrm{R}-\mathrm{B}}$ values more than $2 \sigma$ above red channel response predicted in the absence of fluorescence were considered significant.

only by PE and water. Third, the PE illuminated in the calibration test was a single molecular species with no confounding fluorescence signal from carotenoids or chlorophyll moieties. Fourth, even the metabolic state of PE can alter its fluorescence response. During active periods of photosynthesis, incoming photonic energy can be transferred to other macromolecular structures instead of being available for fluorescence release of a lower-energy photon. Finally, a laser beam targeting an organism in a translucent ice matrix instead of in liquid water can be affected by multiple air/ice boundaries as it encounters random air bubbles. The reflection or refraction of all or portions of the incident beam can produce any of four results: illumination of the prime target only; prime target illumination plus reflected illumination of one or more targets lateral to the original laser path; penetration of the prime and multiple deeper targets along the original laser light path; and/or both primary and secondary targets missed completely. These characteristics make a calibration with known PE standards challenging since in situ conditions are very difficult to mimic in artificial ice cores.

The current work has demonstrated that an inexpensive, easily transported compact digital camera and a $532 \mathrm{~nm}$ laser pen light make it possible to generate laser-induced fluorescence imaging signatures for cryoconites in clear translucent Antarctic lake ice. It has also been shown that the photosynthetic biomass is persistent within the upper layer of Lake Fryxell ice cover in a core of $27 \mathrm{~cm}$ depth. Ice from the McMurdo Dry Valley lakes usually contains sediment inclusions associated with cyanobacteria to $\sim 2 \mathrm{~m}$ depth, hence a more detailed study regarding the penetration of the laser into deeper layers would be valuable to understand the distribution of photosynthetic pigments in the ice cover. Future experiments are required, however, to assess the impact of sediment inclusions and ice bubbles causing absorption and/or scattering of the laser beam when it comes to a final conversion from fluorescence signal to PE concentrations. 


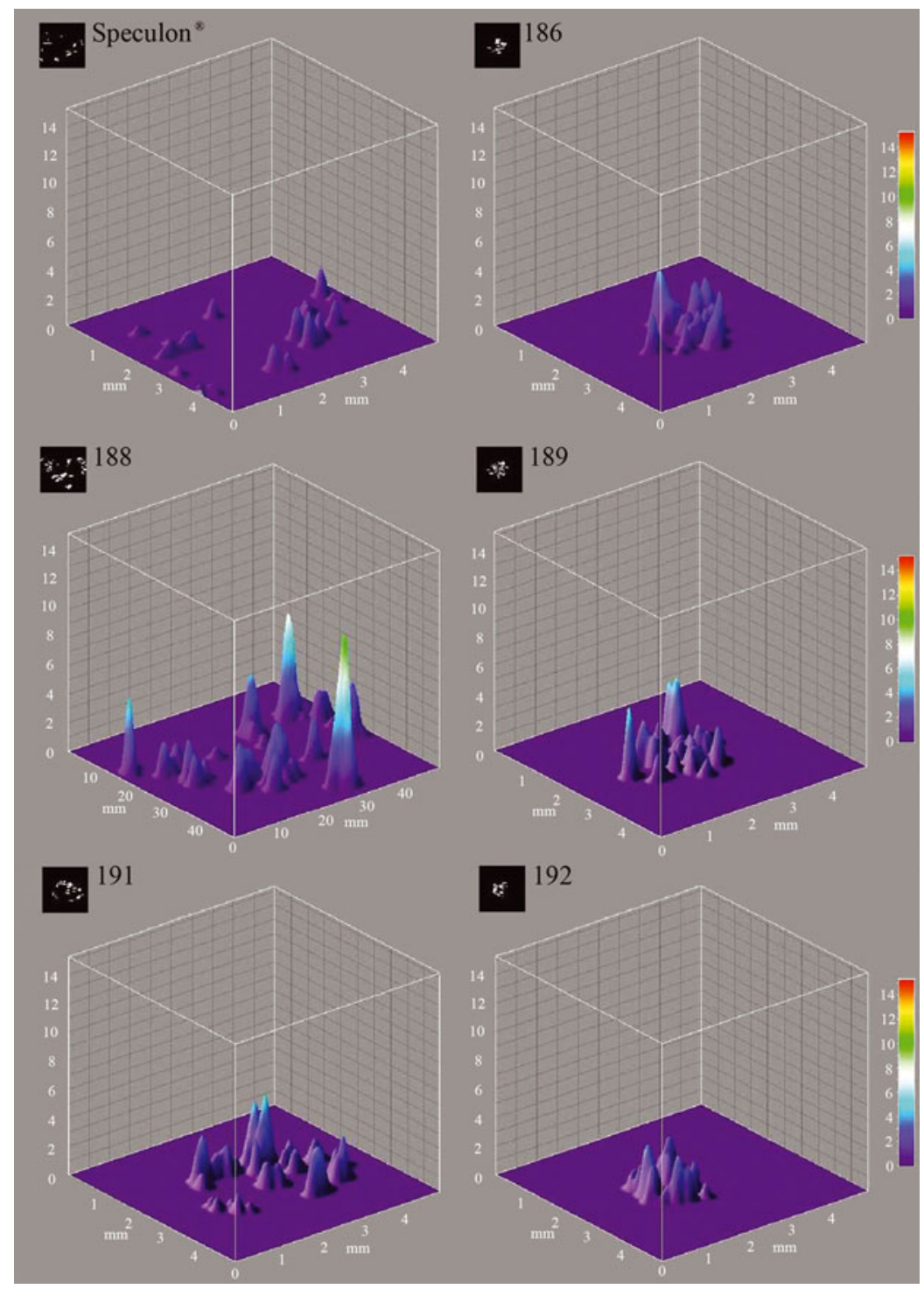

Fig. 7. Light profiles for fluorescence images (from ROIs 186-192 including Speculon ${ }^{\circledR}$ ) depicted for visual comparison with Speculon ${ }^{\circledR}$ control light curves. The $5 \mathrm{~mm} \times 5 \mathrm{~mm}$ fluorescence image as the ROI is used to generate each set of light curves appears in the upper left corner.

\section{ACKNOWLEDGEMENTS}

We thank the Alpine Research Station Obergurgl (AFO) and the Austrian Ministry for Science and Research (bm.wf, Sparkling Science), Kinohi Institute and TAWANI Foundation for financial and logistical support required for this study. B.S. and C.F. were supported by a grant from the US National Science Foundation (NSF OPP 0838970) to C.F.

\section{REFERENCES}

Anesio, A.M., A.J. Hodson, A. Fritz, R. Psenner and B. Sattler. 2009. High microbial activity on glaciers: importance to the global carbon cycle. Global Change Biol., 15(4), 955-960.

Anesio, A.M. and 6 others. 2010. Carbon fluxes through bacterial community on glacier surfaces. Ann. Glaciol., 51(56) (see paper in this issue).

Asher, S.A. 1993. UV resonance Raman spectroscopy for analytical, physical, and biophysical chemistry. Part 1. Anal. Chem., 65(2), 59A-66A.

Bhatia, R. and 9 others. 2008. Classification of organic and biological materials with deep ultraviolet excitation. Appl. Spectrosc., 62(10), 1070-1077.

Blinks, L.R. 1954. The photosynthetic function of pigments other than chlorophyll. Annu. Rev. Plant Physiol., 5, 93-114.
Erokhina, L.G., A.V. Shatilovich, O.P. Kaminskaya and D.A. Gilichinskii. 2002. The absorption and fluorescence spectra of the cyanobacterial phycobionts of cryptoendolithic lichens in the high-polar regions of Antarctica. Microbiology, 71(5), 601-607.

Fisk, M.R., M.C. Storrie-Lombardi, S. Douglas, R. Popa, G. McDonald and C. Di Meo-Savoie. 2003. Evidence of biological activity in Hawaiian subsurface basalts. Geochem. Geophys. Geosyst., 4(12), 1103. (10.1029/2002GC00038.)

Foreman, C.M., B. Sattler, D.L. Mikucki, D.L. Porazinska and J.C. Priscu. 2007. Metabolic activity and diversity of cryoconites in the Taylor Valley, Antarctica. J. Geophys. Res., 112(G4), G04S32. (10.1029/2006JG000358.)

Fritsen, C.H. and J.C. Priscu. 1998. Photosynthetic characteristics of cyanobacteria in permanent ice covers on lakes in the McMurdo Dry Valleys, Antarctica. Antarct. J. US, 31(2), 1996 Rev. Issue (NSF 98-28), 216-218.

Gantt, E. 1969. Properties and ultrastructure of phycoerythrin from Porphyridium cruentum. Plant Physiol., 44(11), 1629-1638.

Griffiths, A.D. and 6 others. 2008. Enhancing the effectiveness of the ExoMars PanCam instrument for astrobiology. Geophys. Res. Abstr., 10, EGU2008-A-09486.

Hodson, A.J., P.N. Mumford, J. Kohler and P.M. Wynn. 2005. The High Arctic glacial ecosystem: new insights from nutrient budgets. Biogeochemistry, 72(2), 233-256. 
Hodson, A. and 7 others. 2008. Glacial ecosystems. Ecol. Monogr., 78(1), 41-67.

Hoge, F.E. and R.N. Swift. 1981. Airborne simultaneous spectroscopic detection of laser-induced water Raman backscatter and fluorescence from chlorophyll a and other naturally occurring pigments. Appl. Opt., 20(18), 3197-3205.

Horneck, G. 2000. The microbial world and the case for Mars. Planet. Space Sci., 48(11), 1053-1063.

Jaraula, C.M.B., F. Kenig, P.T. Doran, J.C. Priscu and K.A. Welch. 2009. Composition and biodegradation of a synthetic oil spilled on the perennial ice cover of Lake Fryxell, Antarctica. Environ. Sci. Technol., 43(8), 2708-2713.

Junge, K., H. Eicken and J.W. Deming. 2004a. Bacterial activity at -2 to $-20^{\circ} \mathrm{C}$ in Arctic wintertime sea ice. Appl. Environ. Microbiol., 70(1), 550-557.

Junge, K., H. Eicken and J.W. Deming. 2004b. A microscopic approach to investigate bacteria under in-situ conditions in Arctic lake ice: initial comparisons to sea ice. In Norris, R. and F. Stootman, eds. Bioastronomy 2002: Life amongst the stars. Proceedings of the 213th International Astronomical Union Symposium, 8-12 July, Great Barrier Reef, Australia. San Francisco, Astronomical Society of the Pacific, 381-388.

Kirschvink, J.L. and 6 others. 2000. Paleoproterozoic snowball Earth: extreme climatic and geochemical global change and its biological consequences. Proc. Natl. Acad. Sci. USA (PNAS), 97(4), 1400-1405.

Miteva, V. 2008. Bacteria in snow and glacier ice. In Margesin, R., F. Schinner, J.-C. Marx and C. Gerday, eds. Psychrofiles: from biodiversity to biotechnology. Berlin, etc., Springer-Verlag, 31-50.

Nealson, K., A. Tsapin and M.C. Storrie-Lombardi. 2002. Searching for life in the Universe: unconventional methods for an unconventional problem. Int. Microbiol., 5(4), 223-230.

Ong, L.J. and A.N. Glazer. 1991. Phycoerythrins of marine unicellular cyanobacteria. I. Bilin types and locations and energy transfer pathways in Synechococcus spp. phycoerythrins. J. Biol. Chem., 266(15), 9515-9527.

Porazinska, D.L., A.G. Fountain, T.H. Nylen, M. Tranter, R.A. Virginia and D.H. Wall. 2004. The biodiversity and biogeochemistry of cryoconite holes from McMurdo Dry Valley glaciers, Antarctica. Arct. Antarct. Alp. Res., 36(1), 84-91.

Price, P.B. 2007. Microbial life in glacial ice and implications for a cold origin of life. FEMS Microbiol. Ecol., 59(2), 217-231.

Priscu, J.C. and B.C. Christner. 2004. Earth's icy biosphere. In Bull, A.T., ed. Microbial diversity and bioprospecting. Washington DC, American Society for Microbiology, 130-145.

Priscu, J.C. and 9 others. 1998. Perennial Antarctic lake ice: an oasis for life in a polar desert. Science, 280(5372), 2095-2098.

Priscu, J.C. and 7 others. 2005. Perennial Antarctic lake ice: a refuge for cyanobacteria in an extreme environment. In Castello, J.D. and S.O. Rogers, eds. Life in ancient ice. Princeton, NJ, Princeton University Press, 22-49.

Psenner, R. 1999. Living in a dusty world: airborne dust as a key factor for Alpine lakes. Water, Air, Soil Pollut., 112(3-4), 217-227.

Psenner, R. and B. Sattler. 1998. Life at the freezing point. Science, 280(5372), 2073-2074.

Psenner, R. and 6 others. 1999. Lake ice microbial communities in Alpine and Antarctic lakes. In Margesin, R. and F. Schinner, eds. Cold-adapted organisms: ecology, physiology, enzymology and molecular biology. Berlin, Springer-Verlag, 17-31.

Rohde, R.A., P. Buford Price, R.C. Bay and N.E. Bramall. 2008. In situ microbial metabolism as a cause of gas anomalies in ice. Proc. Natl. Acad. Sci. USA (PNAS), 105(25), 8667-8672.

Samsonoff, W.A. and R. MacColl. 2001. Biliproteins and phycobilisomes from cyanobacteria and red algae at the extremes of habitat. Arch. Microbiol., 176(6), 400-405.
Sattler, B. and M.C. Storrie-Lombardi. 2010. L.I.F.E. in Antarctic lakes. In Bej, A.K., J. Aislabie and R.M. Atlas, eds. Polar microbiology: the ecology, biodiversity and bioremediation potential of microorganisms in extremely cold environments. Boca Raton, FL, CRC Press, 95-114.

Sattler, B., H. Puxbaum and R. Psenner. 2001. Bacterial growth in supercooled cloud droplets. Geophys. Res. Lett., 28(2), 239-242.

Sattler, B., S. Waldhuber, H. Fischer, H. Semmler, P.P. Sipiera and R. Psenner. 2004. Microbial activity and phylogeny in ice cores retrieved from Lake Paula, a newly detected freshwater lake in Antarctica. In Hoover, R.B., G.V. Levin and A.Y. Rozanov, eds. Instruments, methods, and missions for astrobiology VIII. Bellingham, WA, Society of Photo-Optical Instrumentation Engineers, 170-179. (SPIE Proceedings 5555.)

Säwström, C., P. Mumford, W. Marshall, A. Hodson and J. Laybourn-Parry. 2002. The microbial communities and primary productivity of cryconite holes in an Arctic glacier (Svalbard $79^{\circ}$ N). Polar Biol., 25(8), 591-596.

Storrie-Lombardi, M.C. and B. Sattler. 2009. Laser-induced fluorescence emission (L.I.F.E.): in situ nondestructive detection of microbial life in the ice covers of Antarctic lakes. Astrobiology, 9(7), 659-672.

Storrie-Lombardi, M.C., W.F. Hug, G.D. McDonald, A.I. Tsapin and K.H. Nealson. 2001. Hollow cathode ion lasers for deep ultraviolet Raman spectroscopy and fluorescence imaging. Rev. Sci. Instr., 72(12), 4452-4459.

Storrie-Lombardi, M.C., J.-P. Muller, M.R. Fisk, A.D. Griffiths, A.J. Coates and R.B. Hoover. 2008a. Epifluorescence surveys of extreme environments using PanCam imaging systems: Antarctica and the Mars regolith. In Hoover, R.B., G.V. Levin, A.Y. Rozanov and P.C. Davies, eds. Instruments, methods, and missions for astrobiology XI. Bellingham, WA, Society of Photo-Optical Instrumentation Engineers, 1-10. (SPIE Proceedings 7097.)

Storrie-Lombardi, M.C., J.-P. Muller, M.R. Fisk, A.D. Griffiths and A.J. Coates. 2008b. Potential for non-destructive astrochemistry using the ExoMars PanCam. Geophys. Res. Lett., 35(12), L12201. (10.1029/2008GL034296.)

Storrie-Lombardi, M.C. and 6 others. 2009. Laser-induced fluorescence emission (L.I.F.E.): searching for Mars organics with a UV-enhanced PanCam. Astrobiology, 9(10), 953-964.

Takeuchi, N. and Z. Li. 2008. Characteristics of surface dust on Ürümqi Glacier No. 1 in the Tien Shan Mountains, China. Arct. Antarct. Alp. Res., 40(4), 744-750.

Takeuchi, N., S. Kohshima and K. Seko. 2001. Structure, formation, and darkening process of albedo-reducing material (cryoconite) on a Himalayan glacier: a granular algal mat growing on the glacier. Arct. Antarct. Alp. Res., 33(2), 115-122.

Taton, A., S. Grubisic, E. Brambilla, R. de Wit and A. Wilmotte. 2003. Cyanobacterial diversity in natural and artificial microbial mats of Lake Fryxell (McMurdo Dry Valleys, Antarctica): a morphological and molecular approach. Appl. Environ. Microbiol., 69(9), 5157-5169.

Tranter, M. and 6 others. 2004. Extreme hydrochemical conditions in natural microcosms entombed within Antarctic ice. Hydrol. Process., 18(2), 379-387.

Tung, H.C., P.B. Price, N.E. Bramall and G. Vrdoljak. 2006. Microorganisms metabolizing on clay grains in 3-km-deep Greenland basal ice. Astrobiology, 6(1), 69-86.

Vincent, W.F. and C. Howard-Williams. 2000. Life on snowball Earth. Science, 287(5462), 2421

Žukauskas, A., P. Vitta, N. Kurilčik, S. Juršánas and E. Bakiená. 2008. Characterization of biological materials by frequencydomain fluorescence lifetime measurements using ultraviolet light-emitting diodes. Opt. Mater., 30(5), 800-805. 